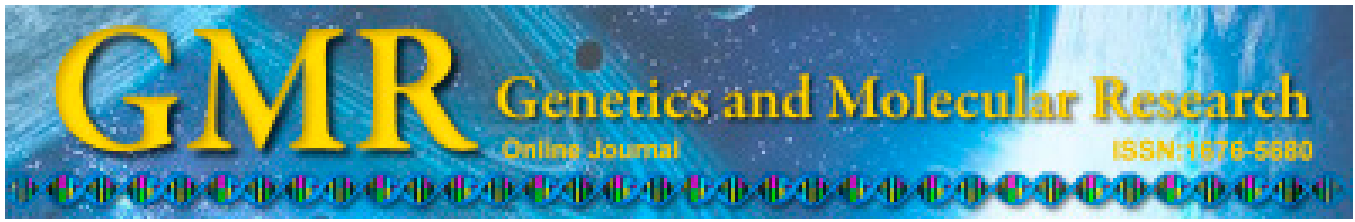

\title{
Relationship between urinary protein changes in lupus nephritis and renal pathology
}

\author{
M. Li ${ }^{1,2}$, W.J. Gao ${ }^{3}$, J.J. Ma ${ }^{2}$, Y. Zhu' ${ }^{2}$ and X.F. Li ${ }^{1}$ \\ ${ }^{1}$ Department of Rheumatology, Qi Lu Hospital, Shandong University, Jinan, \\ Shandong, China \\ ${ }^{2}$ Department of Rheumatology, Weifang People's Hospital, Weifang, \\ Shandong, China \\ ${ }^{3}$ Department of Ultrasonography, Weifang People's Hospital, Weifang, \\ Shandong, China \\ Corresponding author: X.F. Li \\ E-mail: XingFuLi234@163.com
}

Genet. Mol. Res. 14 (3): 8352-8358 (2015)

Received October 28, 2014

Accepted April 24, 2015

Published July 28, 2015

DOI http://dx.doi.org/10.4238/2015.July.28.1

\begin{abstract}
This study investigated the relationship between urinary protein excretion in lupus nephritis New Zealand black mice and renal pathology. A total of 328 lupus nephritis New Zealand black mice were established by a backcross hybridization method, and renal pathology was determined. The urinary protein excretion of the backcross mice over $24 \mathrm{~h}$ was compared and analyzed. Urinary protein excretion over $24 \mathrm{~h}$ differed significantly across different pathological types $(1.9,2.4$, 2.9 and $4.9 \mathrm{~g}$ in types II, III, IV, and V, respectively) in the backcross mice $(\mathrm{P}<0.05)$. Moreover, it correlated with pathology grade $(\mathrm{r}=$ $0.391, \mathrm{P}=0.0001)$ as well as activity index, chronic index, renal tubular interstitial activity index, and renal tubular interstitial lesions $(\mathrm{P}<0.05)$ but not with vascular lesions $(\mathrm{P}=0.683)$. Urinary protein excretion from lupus nephritis is closely associated with renal pathology. Urinary
\end{abstract}


protein changes can be used to determine lupus nephritis pathology and have some clinical significance for treatment and prognosis.

Key words: Lupus nephritis; Urinary protein; Pathological type

\section{INTRODUCTION}

Lupus nephritis accounts for a large proportion of secondary glomerular disease. Clinical symptoms include hematuria, proteinuria, and renal failure (Bisgaard et al., 2014). Urinary protein changes are of great significance in evaluating lupus activity, treatment effect, and prognosis; they can also aggravate renal function deterioration (Stitt et al., 2014). Thus, the relationship between urinary protein changes and the pathological type of lupus nephritis is particularly important. This study aimed to investigate the relationship between urinary protein excretion and pathological types of lupus nephritis, via the generation of mouse models.

\section{MATERIAL AND METHODS}

\section{Materials}

The slicing knife was purchased from Philas Co., Ltd. (Changzhou, China). The microtome was from Hubei Taikang Medical Equipment Co., Ltd. (cat. No. TKY-QPB, Xiaogan, China). The incubator was from Sanyo (cat. No. MCO-15AC). The microscope was from Olympus (cat. No. CX31-32). Hematoxylin and eosin staining kits were from Beijing Labest Biological Co., Ltd. Periodic acid Schiff staining kits were purchased from Shanghai Bogoo Biotechnology Co., Ltd. Periodic Schiff-methenamine staining kits were from Beijing Huanyu Golden Eagle Technology Co., Ltd. The Masson staining kit was purchased from Eysin Technology Co., Ltd. IgA, IgG, IgM, C3, C1q, and FRA kits were from Nanjing Senbeijia Biological Technology Co., Ltd.

\section{Experimental animals}

NZB, NZW, and (NZB XNZW) F1 mice were purchased from Shandong University. A total of 328 F1 backcross mice were generated from female NZB/NZW F1 mice and male NZW mice. All animals were housed in a specific pathogen free grade facility. All animal procedures were approved by the Ethics Committee of our hospital.

\section{Methods}

\section{Urinary protein detection}

The urinary protein of backcross mice was measured twice per week starting at 4 months of age. The degree of renal damage was categorized according to the urinary protein level (Chávez Valencia et al., 2014); i.e., level 0: less/equal to $37 \mathrm{mg}$; level 1: more than $37 \mathrm{mg}$ and less/equal to $74 \mathrm{mg}$; level 2: more than $74 \mathrm{mg}$ and less/equal to $111 \mathrm{mg}$; level 3: more than $111 \mathrm{mg}$ and less/equal to $333 \mathrm{mg}$; level 4: more than $333 \mathrm{mg}$ and less/equal to $1000 \mathrm{mg}$; level 
5: more than $1000 \mathrm{mg}$ and less/equal to $3000 \mathrm{mg}$; level 6: more than $3000 \mathrm{mg}$. A urinary protein level continuously exceeding level 3 can be diagnosed as lupus nephritis (Qi et al., 2013).

\section{Pathological type determination}

The mice were euthanatized, and their kidneys were resected. The kidneys were observed by light microscopy (hematoxylin and eosin, periodic acid-Schiff, periodic acid-Schiffmethenamine, and Masson staining) and immunofluorescence (IgA, IgG, IgM, C3, C1q, and FRA staining). Some specimens were observed by electron microscopy. Lupus nephritis pathological classification was based on the 2010 version of the ISN/RPS standard (Kryvenko et al., 2014). The Austin standard was applied for the semi-quantitative scoring of the changes in lesion activity and chronicity degree (Wang et al., 2014). The (-) to (+++) status of each lesion was scored from 0 to 3, respectively, and presented as the activity index (AI), chronic index (CI), renal tubular interstitial activity index (IAI), renal tubular interstitial lesions (TIL), and vascular lesions (VL).

\section{Statistical analysis}

SPSS version 17.0 (SPSS Inc., Chicago, IL, USA) was used for data analysis. ANOVA, Pearson's and Spearman's correlation analyses, and multiple-regression analysis were performed. The level of significance was set at $\mathrm{P}<0.05$.

\section{RESULTS}

\section{Relationship between lupus nephritis pathological type and urinary protein level}

Among the 328 lupus nephritis backcross mice, urinary protein level varied greatly with respect to pathological type. Urinary protein level was the highest in lupus nephritis type $\mathrm{V}(4.3 \pm 0.9 \mathrm{~g})$, followed by type VI $(2.9 \pm 0.2 \mathrm{~g})$. Lupus nephritis pathological type significantly correlated with 24 -h urinary protein $(\mathrm{r}=0.399, \mathrm{P}<0.05$; Table 1$)$.

\begin{tabular}{lcc}
\multicolumn{2}{c}{ Table 1. Relationship between lupus nephritis pathological type and urine protein level. } \\
\hline Group & $\%(\mathrm{~N})$ & $24-\mathrm{h}$ urine protein $(\mathrm{g})$ \\
\hline Lupus nephritis type I & $0.91(3 / 328)$ & $0.57 \pm 0.059^{\mathrm{b}}$ \\
Lupus nephritis type II & $15.24(50 / 328)$ & $1.9 \pm 0.81^{\mathrm{a}}$ \\
Lupus nephritis type III & $14.33(47 / 328)$ & $2.4 \pm 0.5^{\mathrm{a}}$ \\
Lupus nephritis type IV & $26.83(88 / 328)$ & $2.9 \pm 0.2^{\mathrm{a}}$ \\
Lupus nephritis type V & $42.07(138 / 328)$ & $4.9 \pm 0.9$ \\
Lupus nephritis type VI & $0.61(2 / 328)$ & $1.76 \pm 0.3^{\mathrm{b}}$ \\
\hline
\end{tabular}

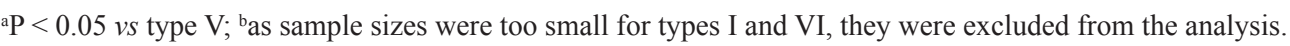

\section{Relationships between urinary protein level and AI, CI, IAI, TIL, and VL}

According to the Austin standard, AI, CI, IAI, and TIL positively correlated with 24-h urinary protein expression $(\mathrm{P}<0.05)$, while $\mathrm{VL}$ did not $(\mathrm{P}>0.05)$. Among them, IAI showed the strongest correlation $(\mathrm{r}=0.24, \mathrm{P}<0.05$; Table 2$)$. 
Table 2. Correlations between urine protein levels and AI, CI, IAI, TIL, and VL.

\begin{tabular}{lccc}
\hline Variable & 24-h urine protein $(\mathrm{g})$ & $\mathrm{r}$ & $\mathrm{P}$ \\
\hline AI & $6.1 \pm 4.1$ & 0.17 & 0.029 \\
CI & $4.2 \pm 1.1$ & 0.22 & 0.02 \\
IAI & $2.9 \pm 1.3$ & 0.24 & 0.001 \\
TIL & $4.3 \pm 2.1$ & 0.21 & 0.002 \\
VL & $1.1 \pm 0.9$ & 0.03 & 0.62 \\
\hline
\end{tabular}

AI: activity index, CI: chronic index, IAI: renal tubular interstitial activity index, TIL: renal tubular interstitial lesions, VL: vascular lesions.

\section{Hematoxylin and eosin staining}

Iron ring lesions, hematoxylin bodies, and necrotizing vasculitis involving the arterioles and capillaries were observed on the pathological slides (Figure 1).

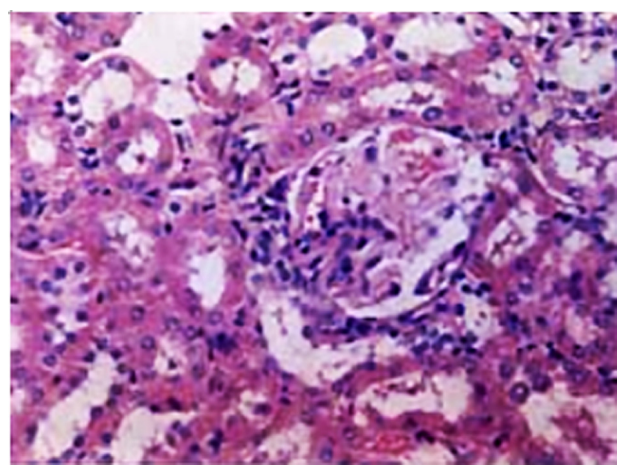

Figure 1. Lupus nephritis pathology. The hematoxylin and eosin staining was used to visualize the tissue morphology of renal cortex. Necrotic lesions can be identified. Magnification: 400X.

\section{Immunofluorescence}

Multi-immunoglobulin deposition was observed on the slides (Figure 2).

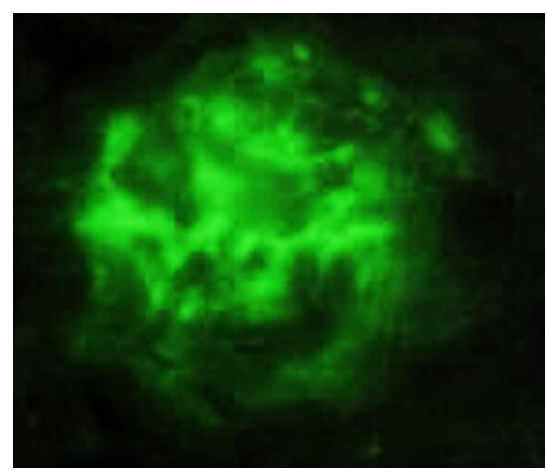

Figure 2. Immunofluorescence of IgG. Multifocal deposition of immunoglobulin (Ig) $\mathrm{G}$ occurred in the renal tissues. Magnification: 400X. 


\section{Electron microscopy}

Virus particles, inclusion bodies, and dense deposits with broken nuclei were observed on electron microscopy (Figure 3).

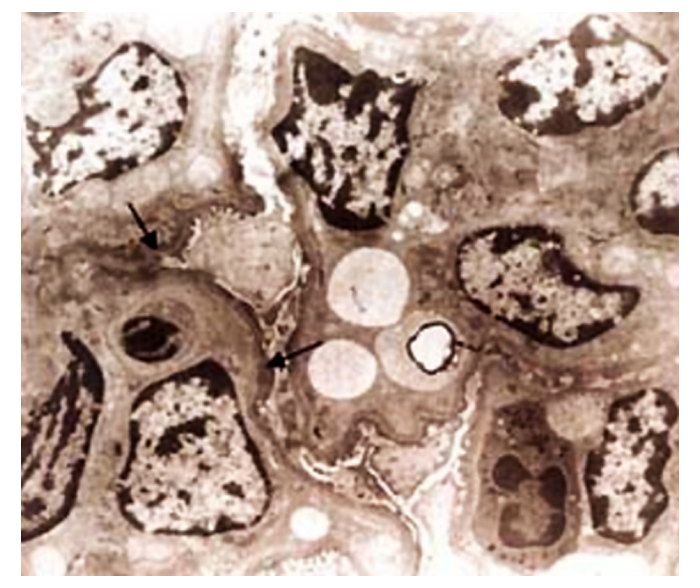

Figure 3. Electron microscopic image of the renal tissue. There were certain viral particles, inclusions and breakdown of nucleus in the renal cell. Magnification: 400X.

\section{DISCUSSION}

Systemic lupus erythematosus (SLE) is a common autoimmune disease. Renal function is often seriously damaged in SLE patients; more serious kidney damage results in poorer prognosis. SLE is often characterized by fever, facial erythema, polymorphism allergic rashes, photosensitization, multiple oral ulcers, arthritis, multiple serositis, vasculitis, nephritis, and central nervous system symptoms. As the condition varies greatly, certain systems or organ lesions may be misdiagnosed or overlooked. Lesions mainly focused on renal damage are called systemic lupus erythroblastosis nephritis and lupus nephritis. Renal pathological type is of great importance for guiding the treatment of lupus nephritis and determining prognosis, while urinary protein content is a marker of renal damage due to lupus nephritis (Cabral et al., 2013; Haddiya et al., 2013; Lateef and Petri, 2013; Mubarak, 2013; Stanković et al., 2013). Renal biopsy is the gold standard for the determination of lupus nephritis pathological type. However, it has several limitations and complications such as low coverage rate in primary hospitals, renal hemorrhage, infection, and cost (Mirfeizi et al., 2012; Abid et al., 2013; Sharifipour et al., 2013).

Backcross mice were the first generation of (NZB XNZW) F1 mice created by hybridizing New Zealand black male NZW mice and New Zealand black female NZB mice. This mouse line can present several lupus nephritis clinical symptoms such as proteinuria, hematuria, and impaired renal function. In particular, the mechanism of kidney damage is roughly the same as that in humans (Li et al., 2012; Shaharir et al., 2012). Therefore, the backcross mouse model is widely used in lupus nephritis and clinical experiments.

In the present study, urinary protein content varied greatly with respect to and was 
significantly correlated with lupus nephritis pathological type. These results suggest that both the kidney pathological type and urinary protein content can be used to evaluate the degree of renal damage, which is consistent with previous reports (Doria and Gatto, 2012). The most common site of renal damage is in the glomeruli; renal blood vessels, interstitium, and tubules are also involved. The results show that AI, CI, IAI, and TIL are significantly correlated with urinary protein content, which is also consistent with previous reports (Takasaki, 2012).

Many researchers suggest that proteinuria is not only an index of the degree of renal damage, but can also lead to renal tubular damage itself. Lupus nephritis often involves the renal tubules, interstitium, and vessels. The renal tubules and interstitium usually present inflammatory cell infiltration, renal tubule degeneration, necrosis, and atrophy. Type IV lupus nephritis patients present severe renal interstitial lesions (i.e., interstitial fibrosis), endothelial cell swelling and necrosis, luminal stenosis, and even necrotizing vasculitis. Immunoglobulin and complement deposited in the stroma, tubular basement membrane, and capillary wall can be detected by immunofluorescence. Proteinuria can promote kidney disease development independently (Xia et al., 2012). Urinary protein content is closely related with renal tubule pathological changes; increase in the urinary protein content is associated with a higher degree of renal tubular damage (Hiraki et al., 2012). This may be because renal tubules release lysosomes and complement protein after reabsorbing protein, while infiltrated renal tubular interstitial cells and inflammatory cells lead to renal tubular atrophy and mesenchymal transition (Jaybhaye et al., 2011; Romick-Rosendale et al., 2011; Singh et al., 2012; Takasaki, 2012; Yahata et al., 2012).

In conclusion, urinary protein is closely related to the renal pathologic type of lupus nephritis. Therefore, the pathological type of lupus nephritis can be determined by analyzing urinary protein content. Furthermore, urinary protein content has clinical significance in the diagnosis, treatment, and prognosis prediction of lupus nephritis. We attempted to decrease patients' mental and physical damage as well as hospitalization expenses by investigating the relationship between urinary protein content and lupus nephritis pathological types in a backcross lupus nephritis mouse model.

\section{Conflicts of interest}

The authors declare no conflict of interest.

\section{ACKNOWLEDGMENTS}

We thank the anonymous reviewers for reviewing this manuscript.

\section{REFERENCES}

Abid N, Khan AS and Al Otaibi FH (2013). Systemic lupus erythematosus (SLE) in the eastern region of Saudi Arabia. A comparative study. Lupus 22: 1529-1533.

Bisgaard H, Jacobsen S, Tvede N and Langhoff-Roos J (2014). Pregnancy complications in a patient with systemic lupus erythematosus and lupus nephritis. Ugeskr Laeger 176: V01140044.

Cabral M, Escobar C, Conde M, Romas M, et al. (2013). Juvenile systemic lupus erythematosus in Portugal: clinical and immunological patterns of disease expression in a cohort of 56 patients. Acta. Reumatol. Port. 38: 274-285.

Chávez Valencia V, Orizaga de La Cruz C, Becerra Fuentes JG, Fuentes Ramírez F, et al. (2014). Epidemiology of glomerular disease in adults: A database review. Gac. Med. Mex. 150: 403-408. 
Doria A and Gatto M (2012). Nephritogenic-antinephritogenic antibody network in lupus glomerulonephritis. Lupus 21: 1492-1496.

Haddiya I, Hamzaoui H, Tachfouti N, Hamany ZA, et al. (2013). Features and outcomes of lupus nephritis in Morocco: analysis of 114 patients. Int. J. Nephrol. Renovasc. Dis. 6: 249-258.

Hiraki LT, Feldman CH, Liu J, Alarcón GS, et al. (2012). Prevalence, incidence, and demographics of systemic lupus erythematosus and lupus nephritis from 2000 to 2004 among children in the US Medicaid beneficiary population. Arthritis Rheum. 64: 2669-2976.

Jaybhaye AP, Sutay NR, Chate SV and Rathod TN (2011). Juvenile systemic lupus erythematosus: A diagnostic dilemma. J. Nat. Sci. Biol. Med. 2: 229-231.

Kryvenko ON, Haley SL, Smith SC, Shen SS, et al. (2014). Haemangiomas in kidneys with end-stage renal disease: a novel clinicopathological association. Histopathology 65: 309-318.

Lateef A and Petri M (2013). Managing lupus patients during pregnancy. Best Pract. Res. Clin. Rheumatol. 27: 435-447.

Li M, Liang Y, Yu WJ, Wu XH, et al. (2012). Peripheral blood leukocyte double strand RNA-dependent protein kinase gene expression in patients with systemic lupus erythematosus. Zhonghua Nei Ke Za Zhi. 51: 855-858.

Mirfeizi Z, Mahmoudi M, Naghibi M, Hatef M, et al. (2012). Urine Monocyte Chemoattractant Protein-1 (UMCP-1) as a Biomarker of Renal Involvement in Systemic Lupus Erythematosus. Iran. J. Basic Med. Sci. 15: 1191-1915.

Mubarak M (2013). Hidden face of lupus nephritis exposed: Isolated tubulointerstitial lupus nephritis. J. Nephropathol. 2: $71-72$.

Qi CJ, Ye BX, Ni ZH, Cao LO, et al. (2013). Analysis of associated factors for remission and relapse in proliferative and membranous lupus nephritis patients: a 4-year follow-up study. Zhonghua Yi Xue Za Zhi 93: 3826-3830.

Romick-Rosendale LE, Brunner HI, Bennett MR, Mina R, et al. (2011). Identification of urinary metabolites that distinguish membranous lupus nephritis from proliferative lupus nephritis and focal segmental glomerulosclerosis. Arthritis Res. Ther. 13: R199.

Shaharir SS, Mohamed Said MS and Kong NC (2012). Predictors of thickened carotid intima media thickness among well controlled lupus nephritis patients in a Malaysian tertiary centre. Reumatismo 64: 341-349.

Sharifipour F, Zeraati A, Sahebari M, Hatef M, et al. (2013). Association of urinary lipocalin-2 with lupus nephritis. Iran. J. Basic Med. Sci. 16: 1011-1015.

Singh S, Wu T, Xie C, Vanarsa K, et al. (2012). Urine VCAM-1 as a marker of renal pathology activity index in lupus nephritis. Arthritis Res. Ther. 14: R164.

Stanković N, Vlahović P and Savić V (2013). Histomorphological and clinical study of primary and secondary glomerulopathies in Southeast Serbia (20-year period of analysis). Vojnosanit Pregl. 70: 1085-1090.

Stitt R, Fernelius C, Roberts J, Denunzio T, et al. (2014). Lupus erythematosus tumidus: a unique disease entity. Hawaii J. Med. Public Health 73: 18-21.

Takasaki Y (2012). Molecular targets and their regulation in systemic lupus erythematosus and lupus nephritis. Nihon Jinzo Gakkai Shi 54: 598-602.

Wang FM, Yu F, Tan Y, Liu G, et al. (2014). The serum levels of connective tissue growth factor in patients with systemic lupus erythematosus and lupus nephritis. Lupus 23: 655-664.

Xia Y, Campbell SR, Broder A, Herlitz L, et al. (2012). Inhibition of the TWEAK/Fn14 pathway attenuates renal disease in nephrotoxic serum nephritis. Clin. Immunol. 145: 108-121.

Yahata M, Takahashi S, Nakaya I, Sakuma T, et al. (2012). Possible IgG4-related kidney disease requiring a differential diagnosis of membranous lupus nephritis. Intern. Med. 51: 1731-1736. 